\title{
EFICÁCIA DE HERBICIDAS NO MANEJO DE Euphorbia heterophylla PARA O PLANTIO DIRETO DE SOJA
}

\author{
Fernando T. de Carvalho ${ }^{1}$, Marcelo R. Mendonça ${ }^{2}$, \\ Maximilian Peruchi ${ }^{2}$ e Rodrigo R. B. Palazzo ${ }^{2}$
}

\author{
' Engenheiro Agrônomo, Dr., Professor. FEIS/UNESP. Av. Brasil, 56. Caixa Postal 31. Ilha Solteira, SP 15385-000 ftadeu@bio.feis.unesp.br \\ ${ }^{2}$ Graduando de Agronomia. FEIST/UNESP.
}

\begin{abstract}
RESUMO
O experimento foi desenvolvido na safra 99/00, na FEP-UNESP-FEIS, em Selvíria-MS, enquadrada em região de Cerrado, em solo com textura média. O objetivo foi avaliar a eficiência agronômica e os efeitos fitotóxicos de herbicidas de pós-emergência no manejo de plantas adultas de Euphorbia heterophylla para o plantio direto de soja. A variedade utilizada foi a 'Tucano'. A semeadura foi realizada em área com plantas adultas de Euphorbia heterophylla, no sistema "plantio direto sobre o mato". Os herbicidas selecionados para o teste experimental foram aplicados na operação de manejo em pós-emergência das plantas daninhas e pré-semeadura da cultura. O delineamento experimental adotado foi o de blocos ao acaso, com seis tratamentos e quatro repetições. Os tratamentos, aplicados um dia antes da semeadura, foram os seguintes: glyphosate (960 e $1920 \mathrm{~g} / \mathrm{ha})$, chlorimuron-ethyl+glyphosate $(10+960 \mathrm{~g} / \mathrm{ha})$, chlorimuronethyl+TY029+glyphosate $(10+10+960 \mathrm{~g} / \mathrm{ha})$ e testemunhas no mato e no limpo. Avaliou-se a eficiência dos herbicidas na dessecação das plantas daninhas, o efeito residual e a seletividade dos tratamentos. Não foram observados sintomas de fitotoxicidade dos tratamentos às plantas de soja. Os tratamentos glyphosate (960 e $1920 \mathrm{~g} / \mathrm{ha}$ ), chlorimuronethyl+glyphosate $(10+960 \mathrm{~g} / \mathrm{ha})$ e chlorimuron-ethyl+TY029+glyphosate $(10+10+960 \mathrm{~g} / \mathrm{ha})$, foram eficientes na dessecação de plantas adultas de E. heterophylla. O herbicida chlorimuron-ethyl $(10 \mathrm{~g} / \mathrm{ha})$ aplicado juntamente com o glyphosate, no manejo, proporcionou ao tratamento um efeito residual significativo para Euphorbia heterophylla, reduzindo a infestação da planta daninha durante o ciclo da cultura da soja.
\end{abstract}

Palavras-chave: Glycine max, glyphosate, chlorimuron-ethyl, TY029.

\section{ABSTRACT \\ Efficacy of postemergence herbicides to control Euphorbia hetrophylla in no-till soybean}

The experiment was carried out in 99/00, at the experimental field of the State University of São Paulo, in Selvíria,MS, on a medium texture soil. The objective of the study was to evaluate the tolerance and agronomic efficacy of postemergence herbicides in the control of adult plants of Euphorbia heterophylla for no-till planting of soybean cv. Tucano. Planting was done in area with adult plants of E. heterophylla, in the system of "direct planting on the weeds". The herbicides were applied in postemergence of the weeds and the culture. Experimental design was a randomized complete block with six treatments and four replications. Treatments, applied one day before planting, were: glyphosate (960 and $1920 \mathrm{~g} / \mathrm{ha}$ ), chlorimuronethyl + glyphosate $(10+960 \mathrm{~g} / \mathrm{ha})$, chlorimuron-ethyl+TY029+glyphosate $(10+10+960 \mathrm{~g} / \mathrm{ha})$ and control with and without weeds. The parameters evaluated were the control of weeds, the residual effect and the crop tolerance. No injury to soybean was observed in any treatment. Glyphosate (960 and $1920 \mathrm{~g} / \mathrm{ha})$, chlorimuron-ethyl+glyphosate $(10+960 \mathrm{~g} / \mathrm{ha})$ and chlorimuronethyl+TY029+glyphosate $(10+10+960 \mathrm{~g} / \mathrm{ha})$, were efficient in the control of adult plants of $E$. heterophylla. The herbicide 
chlorimuron-ethyl (10 g/ha) applied together with glyphosate, on adult weeds, provided residual effect for E. heterophylla, reducing the occurrence of the weed during the entire soybean cycle.

Key words: Glycine max, glyphosate, chlorimuron-ethyl, TY029.

\section{INTRODUÇÃO}

Vários trabalhos publicados, baseados em médias mundiais, situam as plantas daninhas como as maiores responsáveis pela queda de produção da soja, em comparação com ataques de pragas e patógenos. Segundo dados da Associação Nacional de Defesa Vegetal - ANDEF (1987), as perdas mundiais de produção de soja, por ano, devido à ocorrência de plantas daninhas, são em média de $13 \%$. Entretanto, no clima tropical do Brasil, tem sido observado perdas bem maiores.

Blanco et al. (1973 e 1978) observaram prejuízos na produtividade da soja que variaram de 42 a $95 \%$, dependendo das espécies daninhas infestantes. Carvalho (1993) observou perdas médias de produtividade de $52,6 \%$ na testemunha infestada em relação à testemunha no limpo, para o cultivar Paraná. Spadotto et al. (1994) observaram perdas médias de produtividade de $42,4 \%$ na testemunha infestada por plantas daninhas de folhas largas, em relação à testemunha no limpo, para a cultivar IAC-8.

O cultivo sem o revolvimento do solo é uma das tecnologias utilizadas na cultura da soja. A prática, conhecida como plantio direto, é utilizada em várias culturas e tem como principal vantagem à conservação do solo. No entanto, um dos principais problemas que tem se detectado no cultivo direto é a ocorrência de plantas daninhas e suas interações com o ambiente, prejudicando as plantas cultivadas.

Existem diferentes métodos para o controle das plantas daninhas. Na cultura da soja, devido às extensas áreas cultivadas, o controle químico é o que tem sido mais utilizado. No plantio direto o controle das invasoras também depende da utilização de herbicidas, uma vez que os cultivos e capinas são incompatíveis com a tecnologia utilizada no sistema.

No plantio direto é importante a utilização de herbicidas de manejo, aplicados antes da semeadura da cultura, para a formação da palhada. Os herbicidas mais utilizados, nesta prática, são os dessecantes sem efeito residual, como o glyphosate e o paraquat. A utilização de herbicidas no manejo, que permitam um efeito residual no solo, poderia ser uma solução para reduzir a infestação de plantas daninhas em pós-emergência da cultura e, consequentemente, provocar uma economia nos custos desta operação.

O objetivo do trabalho foi avaliar a eficácia agronômica e os efeitos fitotóxicos de herbicidas aplicados em pósemergência no manejo de plantas adultas de Euphorbia heterophylla, para o plantio direto de soja.

\section{MATERIAL E MÉTODOS}

O experimento foi desenvolvido no período de dezembro de 1999 a maio de 2000, na Fazenda de Ensino e Pesquisa (FEP) da UNESP - FEIS, situada à 20 $22^{\prime}$ 'de latitude sul, 51을 de longitude oeste, 335 metros de altitude e localizada no município de Selvíria, MS, enquadrada em região de Cerrado, no sudeste do Mato Grosso do Sul. O solo da área experimental é classificado como Latossolo Vermelho-Escuro, textura média, com $32 \%$ de argila, $66 \%$ de areia e $2 \%$ de silte. O teor de matéria orgânica era de 1,8\% e o pH (em água) de 5,5. A quantidade de chuvas ocorridas durante o experimento está apresentada no Anexo 1.

A variedade de soja utilizada foi a 'Tucano', semeada mecanicamente em 21/12/99, no espaçamento de $0,50 \mathrm{~m}$ entre linhas. A semeadura foi realizada em área com plantas adultas de Euphorbia heterophylla, no sistema "plantio direto sobre o mato". A emergência ocorreu em sete dias.

Os tratos culturais realizados na área experimental foram os normais exigidos pela cultura, no que diz respeito às adubações e ao controle de pragas e doenças. Para o controle de doenças iniciais tratou-se as sementes com o fungicida benomyl ( $50 \mathrm{~g} / 100 \mathrm{~kg}$ sementes). Antes da semeadura, realizou-se a inoculação das sementes, utilizando-se o produto Emerge $\mathrm{PM}$ à base de 20 gramas, diluídos em $600 \mathrm{ml}$ de água, para $80 \mathrm{~kg}$ de sementes. A adubação foi realizada concomitantemente à semeadura, utilizando-se $250 \mathrm{~kg} / \mathrm{ha}$ da fórmula comercial 4-30-10.

Foram realizadas duas aplicações de inseticida e fungicida, na época do florescimento e enchimento de grãos da cultura, para o controle de lagartas e percevejos e para a prevenção de doenças. Os produtos utilizados foram o inseticida endossulfan (350 g/ha) e o fungicida benomyl (250 g/ha). As aplicações foram realizadas com um pulverizador de barra tratorizado e volume de calda de $200 \mathrm{l} / \mathrm{ha}$.

Os herbicidas selecionados para o teste experimental foram aplicados na operação de manejo, em pós-emergência das plantas daninhas e pré-semeadura da cultura. No tratamento testemunha no limpo a operação de manejo foi realizada mecanicamente, através de enxadas, e o controle das plantas daninhas aos 15 e 30 dias após a semeadura. Nos demais tratamentos não foi realizado o controle das plantas daninhas em pós-emergência da cultura, com o intuito de não se mascarar o efeito residual dos herbicidas aplicados na dessecação.

O delineamento experimental adotado foi o de blocos ao acaso, com seis tratamentos e quatro repetições. Cada parcela constou de oito linhas da cultura com $5 \mathrm{~m}$ de comprimen- 
to $4 \mathrm{~m}$ de largura, totalizando $20 \mathrm{~m}^{2}$. A área total do experimento ( $20 \mathrm{~m}^{2} \times 24$ parcelas $)$ foi de $480 \mathrm{~m}^{2}$. Os tratamentos utilizados no experimento estão apresentados na Tabela 1.

As aplicações dos herbicidas foram realizadas com um pulverizador costal com pressão constante $\left(\mathrm{CO}_{2}\right)$ de 40 psi, provido de tanque com capacidade de dois litros (garrafas descartáveis), e com barra equipada com quatro bicos do tipo leque, Teejet $110.03 \mathrm{XR}$, espaçados de $0,5 \mathrm{~m}$. O volume de calda aplicado foi de $250 \mathrm{l} / \mathrm{ha}$. As aplicações foram realizadas em pós-emergência das plantas daninhas, no dia 20/12/99, das 20:00 às 21:00 horas. Na ocasião, o solo encontrava-se com pouca umidade superficial, a temperatura do ambiente, marcada no início, foi de $29^{\circ} \mathrm{C}$, umidade relativa do ar de $72 \%$ e a velocidade do vento inferior a $5 \mathrm{~km} / \mathrm{h}$.

A eficácia dos herbicidas na dessecação das plantas daninhas foi avaliada aos 7 e 21 dias após a aplicação (DAA) dos tratamentos. Utilizou-se uma escala visual onde $0 \%=$ nenhum controle e $100 \%=$ controle total das plantas daninhas. Considerou-se como eficiente o controle superior a $80 \%$. Avaliou-se também a reinfestação das plantas de Euphorbia heterophylla nos tratamentos, através de notas de porcentagem de infestação (visual) aos 7 e 21 DAA e através da contagem do número de plantas $/ \mathrm{m}^{2}$ (em $1 \mathrm{~m}^{2}$ no centro da parcela) aos 30 DAA.

Com relação à seletividade, os dados não estão apresentados no trabalho pois não foi observado nenhum tipo de fitotoxicidade às plantas da cultura. A avaliação de produtividade foi realizada aos 140 dias após a semeadura (10/05/00), coletando-se os grãos da área útil, ou seja, nos $2 \mathrm{~m}^{2}$ centrais de cada parcela.

As comparações entre as médias dos tratamentos foram realizadas pelo teste de Tukey a $5 \%$ de probabilidade.

\section{RESULTADOS E DISCUSSÃO}

A infestação de Euphorbia heterophylla na área experimental, antes da aplicação dos herbicidas, pode ser observada na Figura 1.

Considerou-se como $100 \%$ de infestação, a cobertura total do solo pelas plantas de amendoim-bravo (Figura 1).

Observa-se, pelos dados de controle das plantas daninhas, que todos os tratamentos proporcionaram elevado controle de Euphorbia heterophylla. O herbicida glyphosate, nas doses de 960 e $1920 \mathrm{~g} / \mathrm{ha}$, foi altamente eficiente no controle da planta daninha, proporcionando níveis médios de dessecação acima de $96 \%$, aos 21 DAA. Esses dados estão de acordo com Lorenzi et al. (2000). O tratamento chlorimuronethyl+glyphosate $(10+960 \mathrm{~g} / \mathrm{ha})$ proporcionou $93 \% \mathrm{de}$ dessecação, aos 21 DAA. O tratamento chlorimuronethyl+TY029+glyphosate $(10+10+960 \mathrm{~g} / \mathrm{ha})$ também foi

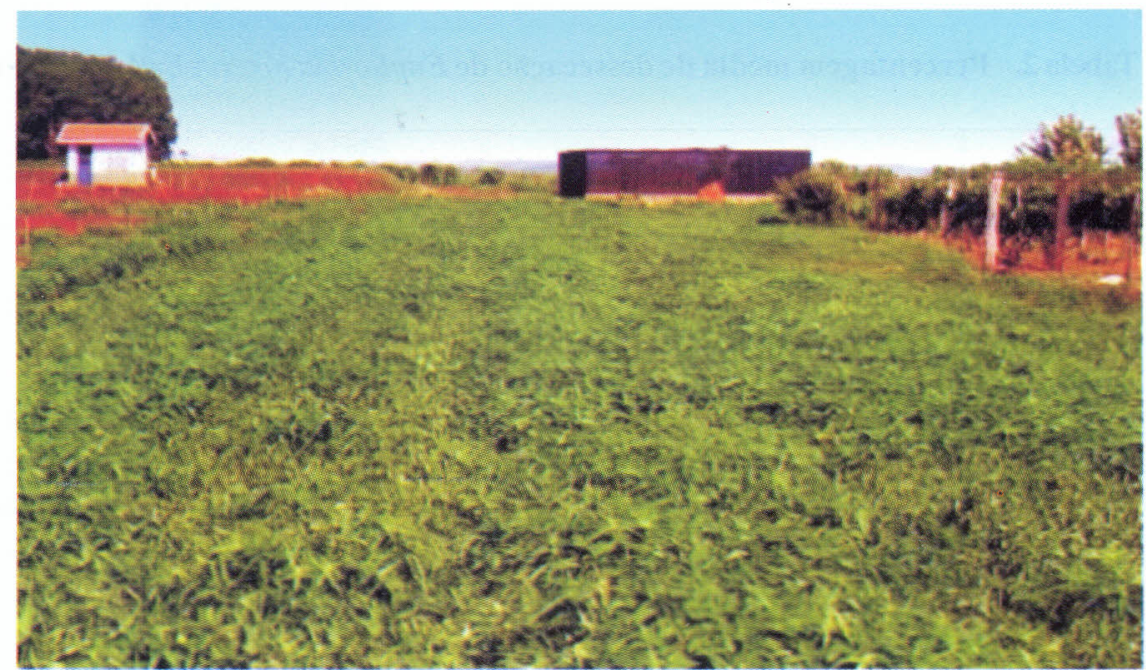

Figura 1. Infestação de Euphorbia heterophylla antes da aplicação dos herbicidas. FEP, Selvíria, MS, 1999-2000.

Tabela 1. Tratamentos utilizados no experimento. FEP, Selvíria, MS, 1999-2000.

\begin{tabular}{|c|c|c|}
\hline \multirow{2}{*}{ Tratamento $^{1}$} & \multicolumn{2}{|c|}{ Dose dos herbicidas } \\
\hline & p.c./ha & i.a. (g/ha) \\
\hline Glyphosate (Roundup) & 2,01 & 960 \\
\hline Glyphosate (Roundup) & 4,01 & 1920 \\
\hline Chlorimuron-ethyl (Classic)+glyphosate (Gliphogan $480 \mathrm{CE}$ ) & $40 \mathrm{~g}+2,01$ & $10+960$ \\
\hline Chlorimuron-ethyl (Classic)+TY029²+glyphosate (Gliphogan $480 \mathrm{CE}$ ) & $40 \mathrm{~g}+20 \mathrm{~g}+2,0 \mathrm{I}$ & $10+10+960$ \\
\hline Testemunha no limpo & -- & -- \\
\hline Testemunha no mato & --- & -- \\
\hline
\end{tabular}

\footnotetext{
' Foi utilizado óleo mineral Assist $(0,5 \%$ v.v.) em todos os tratamentos químicos.
}

${ }^{2}$ TY029 = DPX-TY029 (não registrado). 
altamente eficiente no controle de E. heterophylla, proporcionando total dessecação da planta daninha aos 21 DAA (Tabela 2).

Os dados de reinfestação de E. heterophylla indicam o efeito residual dos herbicidas no controle das plantas daninhas. Observa-se que a reinfestação nos tratamentos com apenas glyphosate (960 e $1920 \mathrm{~g} / \mathrm{ha}$ ) foi bastante alta, maior que $70 \%$, aos $21 \mathrm{DAA}$, enquanto que nos demais tratamentos a reinfestação foi menor que $30 \%$ (Tabelas 3 e 4 ).

A reinfestação nos tratamentos com $10 \mathrm{~g} / \mathrm{ha}$ de chlorimuron-ethyl foi menor que $28 \%$, aos 21 DAA, e o número de plantas $/ \mathrm{m}^{2}$, em relação à testemunha, foi menor que $33 \%$, aos 30 DAA, enquanto que nos tratamentos com glyphosate isolado foi maior que $90 \%$. Esses dados demonstram a ocorrência de um efeito residual do herbicida, proporcionando o controle das plantas daninhas ao longo do tempo.

Este tipo de controle residual, conseguido na operação de manejo, é bastante interessante pois além de reduzir a competição das plantas daninhas no período crítico da cultura, facilita o controle em pós-emergência, que pode ser realizado com doses mínimas de herbicidas recomendados. Resultados semelhantes, obtidos com o herbicida chlorimuron-ethyl, foram recentemente relatados por Valente \& Ornelas (2000) para a espécie Bidens pilosa, e por Bizzi \& Bianchi (2000) para as espécies B. pilosa, Xanthium strumarium e Sida rhombifolia.

A estratégia de se utilizar herbicidas no manejo, que, além de aumentar o espectro de controle do glyphosate, proporcionam efeito residual para o controle das plantas daninhas, já é amplamente utilizada há algum tempo com o herbicida 2,4-D. Rossetto et al. (2000) mostraram os benefícios deste tipo de aplicação em sete ensaios realizados na safra 99/00. Entretanto, a utilização do herbicida 2,4-D no manejo para o plantio direto da soja possui algumas restrições, como a necessidade de se esperar, no mínimo, 10 dias entre a aplicação e a semeadura (Rodrigues \& Almeida, 1998) e a possibilidade de ocorrência de danos à cultura quando há pouca umidade no solo.

Tabela 2. Percentagem média de dessecação de Euphorbia heterophylla. FEP, Selvíria, MS 1999-2000.

\begin{tabular}{|c|c|c|c|}
\hline \multirow{2}{*}{ Tratamento } & \multirow{2}{*}{$\begin{array}{c}\text { Dose } \\
\text { (g/ha) }\end{array}$} & \multicolumn{2}{|c|}{ Dessecação (\%) } \\
\hline & & $7 \mathbf{D A A}^{1}$ & 21 DAA \\
\hline Glyphosate & 960 & $70 \mathrm{c}$ & $96 \mathrm{ab}^{2}$ \\
\hline Glyphosate & 1920 & $88 \mathrm{~b}$ & 100 a \\
\hline Chlorimuron-ethyl+glyphosate & $10+960$ & $70 \mathrm{c}$ & $93 \mathrm{~b}$ \\
\hline Chlorimuron-ethyl+TY029+glyphosate & $10+10+960$ & $90 \mathrm{ab}$ & $100 \mathrm{a}$ \\
\hline Testemunha no limpo & --- & 100 a & 100 a \\
\hline Testemunha no mato & --- & $0 \mathrm{~d}$ & $0 \mathrm{c}$ \\
\hline Média Geral & & 69,8 & 81,6 \\
\hline Teste $\mathrm{f}$ (tratamentos) & & $207,7^{* *}$ & $947,2 * *$ \\
\hline Coeficiente de Variação (\%) & & 7,2 & 3,2 \\
\hline DMS $(5 \%)$ & & 11,6 & 6,0 \\
\hline
\end{tabular}

'DAA = Dias Após a Aplicação dos Herbicidas

${ }^{2}$ Médias seguidas de letras iguais, nas colunas, não diferem entre si pelo teste de Tukey a $5 \%$ de probabilidade.

Tabela 3. Percentagem média de reinfestação das plantas de Euphorbia heterophylla. FEP, Selvíria, MS, $1999-2000$.

\begin{tabular}{lccc}
\hline \multicolumn{1}{c}{ Tratamento } & $\begin{array}{c}\text { Dose } \\
\text { (g/ha) }\end{array}$ & \multicolumn{2}{c}{ Reinfestação (\%) $^{1}$} \\
\cline { 3 - 4 } & 960 & 7 DAA $^{2}$ & 21 DAA \\
\hline Glyphosate & 1920 & 72 & 71 \\
Glyphosate & $10+960$ & 20 & 27 \\
Chlorimuron-ethyl+glyphosate & $10+10+960$ & 21 & 28 \\
Chlorimuron-ethyl+TY029+glyphosate & --- & -- & -- \\
Testemunha no limpo & --- & -- & - \\
Testemunha no mato & & & - \\
\hline
\end{tabular}

${ }^{1}$ Avaliação visual

${ }^{2} \mathrm{DAA}=$ Dias Após a Aplicação dos Herbicidas

Obs.: não foi realizada a análise estatística pois não há dados de reinfestação para os tratamentos 5 e 6 . 
A possibilidade de se realizar a semeadura logo após a operação de manejo, utilizando-se herbicidas seletivos, possui a vantagem de explorar ao máximo o efeito residual dos herbicidas e, consequentemente, aumentar as condições para a cultura fechar no limpo. Essa condição é conhecida como "dianteira competitiva" e foi explorada pelos tratamentos utilizados no presente trabalho.

Os dados de produtividade confirmam os efeitos prejudiciais da competição entre cultura e plantas daninhas, já constatados por outros autores (Blanco et al., 1973 e 1978; Barros et al., 1992; Carvalho, 1993; Spadotto et al., 1994). A convivência com as plantas daninhas prejudicou significativamente a produtividade da cultura no tratamento testemunha no mato (Tabela 5).

\section{CONCLUSÕES}

Os tratamentos com glyphosate isolado e glyphosate+chlorimuron-ethyl aplicados antes da semeadura da cultura, no manejo de plantas daninhas para o plantio direto, não causam fitotoxicidade nas plantas de soja, variedade 'Tucano'.

Os tratamentos glyphosate (960 e $1920 \mathrm{~g} / \mathrm{ha})$, chlorimuron-ethyl+glyphosate (10+960 g/ha) e chlorimuronethyl+TY029+glyphosate $(10+10+960 \mathrm{~g} / \mathrm{ha})$, são eficientes na dessecação de plantas adultas de Euphorbia heterophylla.

O herbicida chlorimuron-ethyl (10 g/ha), aplicado juntamente com o glyphosate, no manejo, proporciona ao

Tabela 4. Número de plantas de E. heterophylla, aos 30 DA A. FEP, Selvíria, MS, 1999-2000.

\begin{tabular}{|c|c|c|c|}
\hline Tratamento & $\begin{array}{l}\text { Dose } \\
\text { (g/ha) }\end{array}$ & $\begin{array}{c}\text { № de plantas } / \mathrm{m}^{2} \\
(30 \text { DAA })^{1}\end{array}$ & $\begin{array}{c}\text { Em relação } \\
\text { à testemunha }(\%)\end{array}$ \\
\hline Glyphosate & 960 & $170 \mathrm{a}$ & 90 \\
\hline Glyphosate & 1920 & 175 a & 93 \\
\hline Chlorimuron-ethyl+glyphosate & $10+960$ & $59 \mathrm{~b}$ & 31 \\
\hline Chlorimuron-ethyl+TY029+glyphosate & $10+10+960$ & $63 \mathrm{~b}$ & 33 \\
\hline Testemunha no limpo & --- & $0 \mathrm{~b}$ & 0 \\
\hline Testemunha no mato & --- & 189 a & 100 \\
\hline Média Geral & & 109,2 & -- \\
\hline Teste f(tratamentos) & & $15,49 * *$ & -- \\
\hline Coeficiente de Variação (\%) & & 36,6 & -- \\
\hline DMS $(5 \%)$ & & 92,0 & -- \\
\hline
\end{tabular}

${ }^{1} \mathrm{DAA}=$ Dias Após a Aplicação dos Herbicidas

${ }^{2}$ Médias seguidas de letras iguais, nas colunas, não diferem entre si pelo teste de Tukey a $5 \%$ de probabilidade.

Tabela 5. Produtividade média da cultura. FEP, Selvíria, MS, 1999-2000.

\begin{tabular}{lcc}
\hline \multicolumn{1}{c}{ Tratamento } & $\begin{array}{c}\text { Dose } \\
\text { (g/ha) }\end{array}$ & $\begin{array}{c}\text { Produtividade } \\
\text { (kg/ha) }\end{array}$ \\
\hline Glyphosate & 960 & $1884 \mathrm{~b}^{1}$ \\
Glyphosate & 1920 & 1928 ab \\
Chlorimuron-ethyl+glyphosate & $10+960$ & $2047 \mathrm{ab}$ \\
Chlorimuron-ethyl+TY029+glyphosate & $10+10+960$ & $2342 \mathrm{ab}$ \\
Testemunha no limpo & --- & $2351 \mathrm{a}$ \\
Testemunha no mato & --- & 499 \\
\hline Média Geral & & 1842 \\
Teste f (tratamentos) & & $46,09 * *$ \\
Coeficiente de Variação (\%) & 11,0 \\
DMS (5\%) & & 465,9 \\
\hline
\end{tabular}

${ }^{1}$ Médias seguidas de letras iguais, nas colunas, não diferem entre si pelo teste de Tukey a $5 \%$ de probabilidade. 
tratamento um efeito residual significativo para Euphorbia heterophylla, reduzindo a infestação da planta daninha durante o ciclo da cultura da soja.

\section{LITERATURA CITADA}

ASSOCIAÇÃO NACIONAL DE DEFENSIVOS AGRÍCOLAS - ANDEF. Defesa vegetal. São Paulo, SP: ANDEF, 1987. $19 \mathrm{p}$.

BARROS, A.C.; MATOS, F.S.A.; NETTO, C.T. Avaliação de herbicidas no controle de plantas daninhas na cultura da soja. Planta Daninha, Brasilia, v. 10, n. 1-2, p. 45 - 49, 1992.

BIZZI, A.F.; BIANCHI, M.A. Eficácia da mistura de chlorimuron-ethyl com glyphosate na dessecação e residual sobre plantas daninhas na soja. In: CONGRESSO BRASILEIRO DA CIÊNCIA DAS PLANTAS DANINHAS, 22. 2000, Foz do Iguaçu - PR. Resumos... Londrina-PR: SBCPD, 2000. p.118.

BLANCO, H.G. et al. Observações sobre o período em que as plantas daninhas competem com a soja [Glycine $\max$ (L.) Merrill]. O Biológico, Campinas, v.39, n.2, p. 31-35, 1973.

BLANCO, H.G., OLIVEIRA, D.A., ARAÚJO, J.B.M. Período crítico de competição de uma comunidade natural de mato em soja [Glycine max (L.) Merrill]. In: SEMINÁRIO NACIONAL DE PESQUISA DE SOJA, 1, 1978, Londrina. Anais... Londrina: EMBRAPA-CNPSO, 1978. p.151-157.
CARVALHO, F.T. Integração de práticas culturais e dosagens de herbicida aplicado em pós-emergência, no controle de plantas daninhas e produtividade da cultura da soja [Glycine max (L.) Merrill]. Jaboticabal: UNESP-FCAV, 1993. 94 p. Dissertação (Mestrado em Agronomia) - Faculdade de Ciências Agrárias e Veterinárias, Universidade Estadual Paulista, 1993.

LORENZI, H. et al. Manual de identificação e controle de plantas daninhas: plantio ditreto e convencional. 5 ed., Nova Odessa-SP: Plantarum, 2000. $339 \mathrm{p}$.

RODRIGUES, B.N.; ALMEIDA, F.S. Guia de herbicidas. 4 ed., Londrina: Edição dos Autores, 1998. 648 p.

ROSSETO, J. et al. Avaliação de herbicidas alternativos ao uso de 2,4-D associados à glyphosate na dessecação de áreas de pousio. In: CONGRESSO BRASILEIRO DA CIÊNCIA DAS PLANTAS DANINHAS, 22., 2000, Foz do Iguaçu - PR. Resumos... Londrina - PR: SBCPD, 2000. p.116.

SPADOTTO, C.A.; MARCONDES, D.A.S.; LUIZ, A.J.B.; SILVA, C.A.R. da. Determinação do período crítico para prevenção da interferência de plantas daninhas na cultura da soja: uso do modelo "broken-stick". Planta Daninha, Brasilia, v. 12, n. 2, p. 59 - 62, 1994.

VALENTE, T.O.; ORNELAS, A. Efeito residual de chlorimuronethyl aplicado em mistura com glyphosate na dessecação em condições de cerrado. In: CONGRESSO BRASILEIRO DA CIÊNCIA DAS PLANTAS DANINHAS, 22., 2000, Foz do Iguaçu - PR. Resumos... Londrina - PR: SBCPD, 2000. p.117. 
Eficácia de herbicidas no manejo

Anexo 1. Dados de precipitação. FEP, Selvíria, MS, 1999-2000.

\begin{tabular}{|c|c|c|c|c|c|c|}
\hline Dia & Dezembro & Janeiro & Fevereiro & Março & Abril & Maio \\
\hline 1 & - & - & 10,8 & 22,7 & - & - \\
\hline 2 & - & 29,5 & - & 60,0 & - & - \\
\hline 3 & - & 1,0 & 16,4 & 10,9 & - & - \\
\hline 4 & - & - & - & 8,2 & - & - \\
\hline 5 & - & 11,0 & 49,0 & 33,6 & - & - \\
\hline 6 & 7,0 & - & 3,0 & - & - & 2,0 \\
\hline 7 & 8,5 & 11,8 & 29,5 & 0,7 & - & - \\
\hline 8 & 32,4 & - & 13,5 & 22,7 & - & - \\
\hline 9 & 6,6 & - & 24,5 & - & - & - \\
\hline 10 & 16,9 & - & 6,3 & 15,1 & 3,3 & $-(*)$ \\
\hline 11 & 5,0 & - & 23,5 & - & - & --------- \\
\hline 12 & 6,5 & - & 67,4 & 2,7 & 7,1 & --------- \\
\hline 13 & 2,5 & 7,2 & 14,2 & - & - & --------- \\
\hline 14 & 11,6 & 4,6 & - & 32,0 & - & --------.-. \\
\hline 15 & - & - & - & 8,9 & - & -------. \\
\hline 16 & - & - & - & 13,8 & - & ------- \\
\hline 17 & - & 29,0 & - & - & 1,7 & - \\
\hline 18 & - & - & - & 20,7 & 14,9 & -------.- \\
\hline 19 & - & 32,4 & - & - & 0,8 & -------- \\
\hline 20 & - & - & - & - & - & --------. \\
\hline 21 & - & - & - & 15,5 & - & -----.--. \\
\hline 22 & - & - & - & - & - & -------. \\
\hline 23 & - & - & - & - & - & -------- \\
\hline 24 & - & - & - & - & - & ------ \\
\hline 25 & 14,5 & 13,0 & - & - & - & -..-- \\
\hline 26 & 4,0 & 31,3 & - & 54,8 & - & - \\
\hline 27 & 3,0 & 5,7 & 10,0 & 12,1 & - & - \\
\hline 28 & - & - & - & - & - & -..--.-- \\
\hline 29 & - & - & 5,2 & - & - & ------ \\
\hline 30 & 24,0 & 5,5 & - & - & - & - \\
\hline 31 & 10,4 & 10,8 & - & - & - & -------- \\
\hline
\end{tabular}

$(*)$ Colheita em 10/05/00. 
